\title{
Killer cell immunoglobulin-like receptors in Thai patients with multiple myeloma
}

\author{
Aphiradee Theeranawakam, ${ }^{1}$ Sasijit Vejbaesya, ${ }^{1}$ Archrob Khuhapinant, ${ }^{2}$ Pradermchai Sae-Tam ${ }^{1}$
}

\begin{abstract}
Background: Natural killer (NK) cells have been implicated in the immune response against multiple myeloma (MM) cells. Killer cell immunoglobulin-like receptors (KIRs) regulate NK cell activity by recognizing specific human leukocyte antigen (HLA) class I as ligands.
\end{abstract}

Objective: To investigate the association of KIR genes and ligands with MM in the Thai population.

Methods: KIR gene polymorphisms and their HLA ligands were investigated in 66 Thai patients with MM and 200 healthy controls.

Results: The frequencies of KIR3DL1 and 2DS4 were significantly lower in myeloma patients than in controls $(P=$ 0.02). The frequencies of KIR3DL1, 2DS4, 2DL1 with C2, and 3DL1 with Bw4 were significantly higher in the patients achieving $>$ very good partial response (VGPR) than those achieving $\leq$ VGPR after treatment with bortezomib $(P=$ $0.009,0.009,0.01$, and 0.02, respectively).

Conclusion: This study suggests the association of KIR genes with the protection against MM and the association of inhibitory KIR and ligands with the response to treatment in MM.

Key words: KIR, multiple myeloma, Thai, NK cell, HLA ligand

\footnotetext{
From:

Department of Transfusion Medicine, Faculty of Medicine, Siriraj Hospital, Mahidol University, Bangkok, Thailand

Department of Medicine, Faculty of Medicine, Siriraj Hospital, Mahidol University, Bangkok, Thailand
}

\section{Introduction}

Multiple myeloma (MM) is a hematological malignancy characterized by the proliferation of clonal plasma cells within the bone marrow. In spite of the improvement in treatment, MM remains largely incurable.

Natural killer (NK) cells are innate lymphoid cells that play an essential role against cancer. The importance of NK cells for the control of myeloma progression has been shown. ${ }^{1}$ In addition, several groups have demonstrated that NK cells can kill MM cell lines. ${ }^{2}$ In early stage myeloma cells, MHC class I downregulation is observed, and myeloma cells are recognized by NK cells. ${ }^{3}$ The killer cell immunoglobulin-like receptors (KIRs) are cell surface receptors of the immunoglobulin superfamily that are expressed on NK cells and subsets of activated or memory $\mathrm{T}$ lymphocytes in humans. KIRs are divided into functional inhibitor groups that prevent target

\author{
Corresponding author: \\ Sasijit Vejbaesya \\ Departmrnt of Transfusion Medicine, Faculty of Medicine, \\ Siriraj Hospital, Mahidol University, \\ 2 Wanglang Road, Bangkok 10700 Thailand \\ E-mail: sasijit.vej@mahidol.ac.th
}

cell lysis and activators that incite cell lysis. KIR molecules with a long cytoplasmic tail (L) transmit inhibitory signals, while those with short cytoplasmic tails (S) send activating signals.

The KIR gene family is encoded within a region of the leukocyte receptor complex on chromosome 19q13.4. Several KIRs use HLA molecules as their ligands. KIR2DL1 and 2DS1 recognize the HLA-C2 group (HLA-C alleles with lysine at position 80 ). KIR2DL2, 2DL3, and 2DS2 recognize the HLA-C1 group (HLA-C alleles with asparagine at position 80). KIR3DL1 recognizes HLA-Bw4. KIR3DL2 recognizes HLA-A3 and A11. The ligands for some activating KIRs remain unknown. The effects of KIRs on host immune responses are mediated by specific interactions between these receptors and HLA class I ligands. ${ }^{4}$ In the populations, 
large heterogeneity in the number and type of KIR genes is observed. ${ }^{5}$ At the haplotype level, two major haplotypes have been defined. The A haplotype is characterized by the presence of inhibitory receptor genes and only one activating gene (KIR2DS4). The B haplotype contains a mixture of activating and inhibitory KIRs.

In hematological malignancies, the associations between KIR genes and HLA ligands have been reported in many diseases; however, the effects vary in different ethnic groups. ${ }^{6}$ In $\mathrm{MM}$, a study in a Lebanese population found an association between activating KIR and MM risk, ${ }^{7}$ and a study in Caucasians found an association between inhibitory KIR/HLA and the outcome of treatment. ${ }^{8}$ However, no study has been performed in Asian populations. The present study was undertaken to investigate the associations of KIR genes and their ligands with $\mathrm{MM}$ in the Thai population.

\section{Materials and methods Study population}

The samples consisted of 66 Thai patients with MM who were diagnosed and treated at the hematology clinic, Department of Medicine, Siriraj Hospital, Bangkok. A control group included 200 healthy Thai individuals from blood donors at Siriraj Hospital. The sample size was calculated from the program n4Studies version 1.4.1. All subjects were interviewed about their ancestry and were from the central Thai ethnic background. Written informed consent was provided by all subjects, and the study was approved by the ethics committee of Siriraj Hospital, Mahidol University, Thailand.

\section{HLA and KIR genotyping}

HLA-C and Bw4 typing were done by polymerase chain reaction with a sequence-specific primer (PCR-SSP). ${ }^{9}$ Validation of the method was done using Micro SSP (One Lambda, Canoga Park, CA) in randomly selected samples and an external quality program. Typing individuals were categorized as HLA-C1 or HLA-C2 on the basis of their genotyping data. HLA-Bw4 was only considered on the HLA-B locus.

The presence or absence of KIR genes was detected using PCR-SSP. ${ }^{10,11}$ The typing method was applied in previous studies and in the external quality control program. ${ }^{12}$ In brief, the $10 \mu \mathrm{L}$ reactions were set up to include $0.1 \mu \mathrm{g}$ of test DNA, buffer IV, $0.2 \mathrm{mM}$ dNTP, $1.08 \mathrm{mM}$ magnesium chloride, 0.3 U Taq DNA polymerase (Roche Diagnostics, Mannheim, Germany), and $0.5 \mu \mathrm{M}$ specific primer mix (except for 3DL1 and 2DS4, which were at a final concentration of $1 \mu \mathrm{M}$ ). Internal controls (5'-CAGTGCCTTCCCAACCATTCC CTTA-3', r 5'-ATCCACTCACGGATTTCTGTTGTG TTTC-3') specific for a 485-base-pair human growth hormone fragment were included at a concentration of $0.067 \mu \mathrm{M}$ in each reaction. No other internal controls were used. All amplifications were performed in duplicate in a Perkin Elmer 9700 (PE Biosystem, California, USA) under thermal cycling conditions as follows: 5 min denaturing step at $94^{\circ} \mathrm{C} ; 10$ cycles of $94^{\circ} \mathrm{C} 10 \mathrm{~s}, 65^{\circ} \mathrm{C}$ $60 \mathrm{~s}$; and 20 cycles of $94^{\circ} \mathrm{C} 10 \mathrm{~s}, 61^{\circ} \mathrm{C} 50 \mathrm{~s}, 72^{\circ} \mathrm{C} 30 \mathrm{~s}$. The products were photographed from standard $1 \%$ agarose electrophoresis gels containing ethidium bromide.

\section{Statistical analysis}

Carrier frequencies for KIR genes and HLA ligands were determined by direct counting. The differences in frequencies between patients and controls were determined by the Chisquare test. Fisher exact tests were performed when relevant. The odds ratios (OR) and 95\% CI were also calculated. $P$ values of less than 0.05 were considered to be significant. Statistical data were calculated using the SPSS version 18.0.

\section{Results}

Diagnosis of MM was based on International Myeloma Working Group updated diagnosis criteria. ${ }^{13}$ The patients included 34 males and 32 females with a mean age at diagnosis of 58.5 years (range of 39-88 years). Fifty-five patients $(83.3 \%)$ received bortezomib-based induction regimens; the others were treated with cyclophosphamide and dexamethasone \pm thalidomide. The patients did not previously have another treatment. The mean time of remission periods was 43.7 months. Thirty-two $(48.5 \%)$ of the patients had relapsed $\mathrm{MM}$, and $11(16.7 \%)$ of the patients were refractory to therapy. Among the patients treated with bortezomib, 38 (69.1\%) achieved more than a very good partial response (> VGPR), while $17(30.9 \%)$ achieved less than or equal to a VGPR ( $\leq$ VGPR). A VGPR was defined as $>90 \%$ reduction in serum $\mathrm{M}$-protein plus urine $\mathrm{M}$-protein levels of $<100 \mathrm{mg}$ per $24 \mathrm{~h}$. The distribution of KIR genes and genotypes in patients and controls is shown in Table 1. No deviations from

Table 1. Frequency of KIR genes and genotypes in patients and controls.

\begin{tabular}{|c|c|c|c|c|}
\hline KIR genes & $\begin{array}{c}\text { MM } \\
\mathbf{N}=66 \\
\text { n (\%) }\end{array}$ & $\begin{array}{c}\text { Control } \\
\mathbf{N}=\mathbf{2 0 0} \\
\text { n (\%) }\end{array}$ & $P$ & $\begin{array}{c}\text { OR } \\
(95 \% \mathrm{CI})\end{array}$ \\
\hline $2 \mathrm{DL} 1$ & $64(97.0)$ & $194(97.0)$ & 1.0 & \\
\hline 2DL2 & $29(43.9)$ & $77(38.5)$ & 0.5 & \\
\hline 2DL3 & $63(95.5)$ & $188(94.0)$ & 1.0 & \\
\hline 2DL5 & $38(57.6)$ & $99(49.5)$ & 0.3 & \\
\hline 3DL1 & $57(86.4)$ & $191(95.5)$ & 0.02 & $\begin{array}{c}0.3 \\
(0.10-0.87)\end{array}$ \\
\hline $2 \mathrm{DS} 1$ & $30(45.5)$ & $82(41.0)$ & 0.2 & \\
\hline 2DS2 & $29(43.9)$ & $76(38.0)$ & 0.5 & \\
\hline $2 \mathrm{DS} 3$ & $18(27.3)$ & $57(28.5)$ & 1.0 & \\
\hline 2DS4 & $57(86.4)$ & $191(95.5)$ & 0.02 & $\begin{array}{c}0.3 \\
(0.10-0.87)\end{array}$ \\
\hline full & $34(51.5)$ & $127(63.5)$ & 0.06 & \\
\hline del & $40(60.6)$ & $118(59.0)$ & 1.0 & \\
\hline 2DS5 & $26(39.4)$ & $63(31.5)$ & 0.3 & \\
\hline 3DS1 & $33(50.0)$ & $83(41.5)$ & 0.3 & \\
\hline \multicolumn{5}{|l|}{ genotypes } \\
\hline AA & $21(31.8)$ & $82(41.0)$ & 0.2 & \\
\hline $\mathrm{Bx}$ & $45(68.2)$ & $118(59.0)$ & 0.2 & \\
\hline
\end{tabular}


Table 2. Frequencies of KIR genes and their ligands in patients and controls.

\begin{tabular}{|lccc|}
\hline Genetic factor & $\begin{array}{c}\text { MM } \\
\mathbf{N}=\mathbf{6 6}, \mathbf{n}(\%)\end{array}$ & $\begin{array}{c}\text { Control } \\
\mathbf{N}=\mathbf{2 0 0}, \mathbf{n}(\%)\end{array}$ & $\boldsymbol{P}$ \\
\hline HLA-C1/C1 & $40(60.6)$ & $127(63.5)$ & 0.7 \\
\hline HLA-C1/C2 & $23(34.8)$ & $60(30.0)$ & 0.5 \\
\hline HLA-C2/C2 & $3(4.5)$ & $13(6.5)$ & 0.6 \\
\hline HLA-Bw4 & $42(63.6)$ & $135(67.5)$ & 0.5 \\
\hline KIR2DL1+C2 & $25(37.9)$ & $71(35.5)$ & 0.7 \\
\hline KIR2DL2+C1 & $29(43.9)$ & $72(36.0)$ & 0.3 \\
\hline KIR2DL3+C1 & $60(90.9)$ & $179(89.5)$ & 0.7 \\
\hline KIR3DL1+Bw4 & $35(53.0)$ & $131(65.5)$ & 0.07 \\
\hline KIR2DS1+C2 & $11(16.7)$ & $31(15.5)$ & 0.8 \\
\hline KIR2DS2+C1 & $29(43.9)$ & $71(35.5)$ & 0.2 \\
\hline KIR3DS1+Bw4 & $24(36.4)$ & $56(28.0)$ & 0.2 \\
\hline
\end{tabular}

Table 3. Frequencies of KIR genes with their ligands and responding to treatment by bortezomib regimen.

\begin{tabular}{|c|c|c|c|c|}
\hline Genetic factor & $\begin{array}{c}>\text { VGPR } \\
\mathbf{N}=38(n \%)\end{array}$ & $\begin{array}{c}\leq \text { VGPR } \\
N=17(n \%)\end{array}$ & $P$ & $\begin{array}{c}\text { OR } \\
(95 \% \mathrm{CI})\end{array}$ \\
\hline HLA-C1/C1 & $19(50.0)$ & $15(88.2)$ & 0.007 & $\begin{array}{c}0.1 \\
(0.02-0.8)\end{array}$ \\
\hline HLA-C1/C2 & $16(42.1)$ & $2(11.8)$ & 0.03 & $\begin{array}{c}5.5 \\
(0.9-40.2)\end{array}$ \\
\hline HLA-C2/C2 & $3(7.9)$ & $0(0.0)$ & 0.9 & \\
\hline HLA-Bw4 & $25(65.8)$ & $10(58.8)$ & 0.6 & \\
\hline KIR3DL1 & $37(97.4)$ & $12(70.6)$ & 0.009 & $\begin{array}{c}15.4 \\
(1.5-386.3)\end{array}$ \\
\hline KIR2DS4 & $37(97.4)$ & $12(70.6)$ & 0.009 & $\begin{array}{c}15.4 \\
(1.5-386.3)\end{array}$ \\
\hline $\mathrm{KIR} 2 \mathrm{DL} 1+\mathrm{C} 2$ & $18(47.4)$ & $2(11.8)$ & 0.01 & $\begin{array}{c}6.8 \\
(1.2-49.6)\end{array}$ \\
\hline KIR2DL2+C1 & $17(44.7)$ & $8(47.1)$ & 0.9 & \\
\hline KIR2DL3+C1 & $33(86.8)$ & $17(100)$ & 0.9 & \\
\hline KIR3DL1+Bw4 & $24(63.2)$ & $5(29.4)$ & 0.02 & $\begin{array}{c}4.1 \\
(1.0-17.1)\end{array}$ \\
\hline KIR2DS1+C2 & $3(7.9)$ & $0(0)$ & 0.2 & \\
\hline $\mathrm{KIR} 2 \mathrm{DS} 2+\mathrm{C} 1$ & $17(44.7)$ & $8(47.1)$ & 0.9 & \\
\hline KIR3DS1+Bw4 & $14(36.8)$ & $6(35.3)$ & 0.9 & \\
\hline
\end{tabular}

VGPR: very good partial response
Hardy-Weinberg proportions were noted for KIR genotypes in both the patients and controls. Framework genes KIR2DL4, KIR3DL2, KIR3DL3, and KIR3DP1 were present in all samples. The frequencies of KIR3DL1 and KIR2DS4 were significantly lower in the patients with myeloma than in the controls $(86.4 \%$ vs. $95.5 \%, P=0.02$, OR $=0.3)$. The frequencies of KIR AA and Bx genotypes were not significantly different between the patients and controls. The frequencies of HLABw4, HLA-C ligands, KIR, and HLA interactions are shown in Table 2. There were no significant differences in the frequencies of HLA-Bw4, HLA-C1, HLA-C2, and KIR genes with their ligands in the patients compared with controls. The effect of KIRs with their ligands and the response to treatment with bortezomib is shown in Table 3. There were no significant differences between patients achieving $>$ VGPR and $\leq$ VGPR with regard to gender, age, and staging. The frequency of HLA-C1/C2 was significantly higher in patients achieving $>$ VGPR than those achieving $\leq$ VGPR $(42.1 \%$ vs. $11.8 \%, P$ $=0.03, \mathrm{OR}=5.5)$, whereas the frequency of HLA-C1/C1 was significantly lower in patients achieving $>$ VGPR than those achieving $\leq$ VGPR (50.0\% vs. $88.2 \%, P=0.007$, OR $=0.1$ ). KIR3DL1 and KIR2DS4 were found to be significantly higher in the patients achieving $>$ VGPR than those achieving $\leq \operatorname{VGPR}(97.4 \%$ vs. $70.6 \%, P=0.009$, OR $=15.4)$. The frequencies of KIR2DL1 with C2 and KIR3DL1 with Bw4 were significantly higher in patients achieving $>$ VGPR than those achieving $\leq \operatorname{VGPR}(P=0.01$ and $P=0.02$, respectively).

\section{Discussion}

We found significantly decreased frequencies of KIR3DL1 and KIR2DS4 in patients with myeloma. KIR3DL1 was found to be in linkage disequilibrium with KIR2DS4. ${ }^{14}$ Analysis of KIR2DS4 full and deletion variants showed no significant difference. This was in contrast with a previous study in the Lebanese population that showed an association between the KIR2DS4 full gene and an increased risk of MM. ${ }^{7}$ However, distributions of KIR2DS4 gene variants in Asian populations are different from those in Lebanese and Caucasian populations. ${ }^{15-18}$ Interestingly, in our study, KIR3DL1 and KIR2DS4 were also significantly increased in the patients with a better response to treatment ( $>$ VGPR) with bortezomib. In addition, KIR3DL1-HLABw4 and KIR2DL1-HLA-C2 were associated with the patients who achieved a better response to bortezomib treatment. This was similar to a previous study in Caucasians that showed an association between KIR3DL1HLA-Bw4 and increased overall response rates and progression-free survival among patients with MM treated with anti-CD38 in combination with lenalidomide and dexamethasone. ${ }^{8}$ In a previous study, KIR3DL1-HLA-Bw4 was also associated with protection against diffuse large B cell lymphoma in Thais. ${ }^{12}$ In other populations, the strong inhibition mediated by KIR2DL1-HLA-C2 and KIR3DL1-HLA-Bw4 in the absence of KIR3DS1 was also found to be associated with protection against cervical neoplasia. ${ }^{19}$ In addition, the patients with KIR3DL1-HLABw4 were found to have a better outcome to treatment in neuroblastoma ${ }^{20}$ and follicular lymphoma. ${ }^{21}$ It was found that inhibitory KIR HLA pairs play a critical role in modulating $\mathrm{NK}$ cell function during $\mathrm{NK}$ development. ${ }^{22}$ 
It is likely that Bw4 delivers a critical signal to KIR3DL1-positive NK cells, and the cells will develop into more potent cytotoxic NK cells..$^{22,23}$ In our study, a higher frequency of heterozygous individuals for HLA-C groups (C1C2) was also found in the group with a better response to treatment. It is likely that patients with HLA-C2 had better outcomes. It was shown that the expression of the HLA-C2 ligand impacts the availability of high-expressing KIR2DL1 ${ }^{24}$ In addition, the education of KIR2DL1 NK cells is controlled by the quantity of ligands, which is similar to the combination of KIR3DL1 and HLA-Bw4. This is the first study of KIR genes in MM in the Thai population. The limitation of this study was the small sample size, especially when divided into groups with response to treatment, which make wide confidence interval in the results. However, we confirmed that KIR3DL1-HLA-Bw4 was associated with a better response to treatment similar to those in Caucasians. Analysis of survival was not performed due to the small sample size. In summary, we found an association between inhibitory KIRs and protection against MM and association between the KIR/HLA ligand and response to treatment. This might suggest the role of KIR genes in MM and may be useful for treatment decisions. Additional studies are needed to clarify the functional significance of KIR genes.

\section{Acknowledgments}

This work was supported by the Siriraj Development Scholarship. This work forms the M.Sc. thesis of Aphiradee Theeranawakam.

\section{Conflict of interest declaration}

The authors declare no conflicts of interest.

\section{References}

1. Khan AM, Devarakonda S, Bumma N, Chaudhry M, Benson DM Jr. Potential of NK cells in multiple Myeloma therapy. Expert Rev Hematol. 2019;12:425-35

2. Frohn C, Höppner M, Schlenke P, Kirchner H, Koritke P, Luhm J. Anti-myeloma activity of natural killer lymphocytes. Br J Haematol. 2002;119:660-4.

3. Fionda C, Stabile H, Molfetta R, Soriani A, Bernardini G, Zingoni A, et al. Translating the anti-myeloma activity of natural killer cells into clinical application. Cancer Treat Rev. 2018;70:255-64.

4. Pende D, Falco M, Vitale M, Cantoni C, Vitale C, Munari E, et al. Killer Ig-Like Receptors (KIRs): Their role in NK cell modulation and developments leading to their clinical exploitation. Front Immunol. 2019;10:1179-97.

5. Falco M, Sivori S, Meazza R, Pende D. Report from the Eleventh Killer Immuno globulin-like Receptor (KIR) Workshop: Novel insights on KIR polymorphism, ligand recognition, expression and function. HLA. 2019;94(2):100-10.

6. Augusto DG. The Impact of KIR Polymorphism on the risk of developing cancer: not as strong as imagined? Front Genet. 2016;7:121-30.
7. Hoteit R, Bazarbachi A, Antar A, Salem Z, Shammaa D, Mahfouz R. KIR genotype distribution among patients with multiple myeloma: higher prevalence of KIR2DS4 and KIR2DS5 genes. Meta Gene. 2014;2:730-6.

8. Marra J, Du J, Hwang J, Wolf JL, Martin TG, Venstrom J. KIR and HLA genotypes influence clinical outcome in multiple myeloma patients treated with SAR650984 (anti-CD38) in combination with lenalidomide and dexamethasone. Blood. 2014;124:2126.

9. Bunce M, O’Neill CM, Barnardo MC, Krausa P, Browning MJ, Morris PJ, et al. Phototyping: comprehensive DNA typing for HLA-A, B, C, DRB1, DRB3, DRB4, DRB5 \& DQB1 by PCR with 144 primer mixes utilizing sequence-specific primers (PCR-SSP). Tissue Antigens. 1995;46:355-67.

10. Kulkarni S, Martin MP, Carrington M. KIR genotyping by multiplex PCR-SSP. Methods Mol Biol. 2010;612:365-75.

11. Martin MP, Carrington M. KIR locus polymorphisms: genotyping and disease association analysis. Methods Mol Biol. 2008;415:49-64.

12. Vejbaesya S, Sae-Tam P, Khuhapinant A, Srinak D. Killer cell immunoglobulin-like receptors in Thai patients with leukemia and diffuse large B-cell lymphoma. Hum Immunol. 2014;75:673-6.

13. Rajkumar SV, Dimopoulos MA, Palumbo A, Blade J, Merlini G, Mateos $\mathrm{MV}$, et al. International meloma working group updated criteria for the diagnosis of multiple myeloma. Lancet Oncol. 2014;15:538-48.

14. Single RM, Martin MP, Mayer D, Gao X, Carrington M. Methods for assessing gene content diversity of KIR with examples from a global set of populations. Immunogenetics. 2008;60:711-25.

15. Denis L, Sivula J, Gourraud PA, Kerdudou N, Chout R, Ricard C, et al Genetic diversity of KIR natural killer cell markers in populations from France, Guadeloupe, Finland, Senegal and Réunion. Tissue Antigens. 2005;66:267-76.

16. Yan LX, Zhu FM, Jiang K, He J. Diversity of the killer cell immunoglobulin-like receptor gene KIR2DS4 in the Chinese population. Tissue Antigens. 2007;69:133-8.

17. Whang DH, Park H, Yoon JA, Park MH. Haplotype analysis of killer cell immunoglobulin-like receptor genes in 77 Korean families. Hum Immunol. 2005 ;66:146-54

18. Bontadini A, Testi M, Cuccia MC, Martinetti M, Carcassi C, Chiesa A, et al. Distribution of killer cell immunoglobulin-like receptors genes in the Italian Caucasian population. J Transl Med. 2006;4:44.

19. Carrington M, Wang S, Martin MP, Gao X, Schiffman M, Cheng J, et al. Hierarchy of resistance to cervical neoplasia mediated by combinations of killer immunoglobulin-like receptor and human leukocyte antigen loci. Exp Med. 2005;201:1069-75.

20. Delgado DC, Hank JA, Kolesar J, Lorentzen D, Gan J, Seo S, et al. Genotypes of NK cell KIR receptors, their ligands, and Fc $\gamma$ receptors in the response of neuroblastoma patients to Hu14.18-IL2 immunotherapy. Cancer Res. 2010;70:9554-61.

21. Erbe AK, Wang W, Carmichael L, Hoefges A, Grzywacz B, Reville PK, et al. Follicular lymphoma patients with KIR2DL2 and KIR3DL1 and their ligands (HLA-C1 and HLA-Bw4) show improved outcome when receiving rituximab. J Immunother Cancer. 2019;7:70-82

22. Kim S, Poursine-Laurent J, Truscott SM, Lybarger L, Song YJ, Yang L, et al. Licensing of natural killer cells by host major histocompatibility complex class I molecules. Nature. 2005;436:709-13.

23. Joncker NT, Fernandez NC, Treiner E, Vivier E, Raulet DH. NK cell responsiveness is tuned commensurate with the number of inhibitory receptors for self-MHC class I: the rheostat model. J Immunol. 2009; 182:4572-80.

24. Le Luduec JB, Boudreau JE, Freiberg JC, Hsu KC. Novel approach to cell surface discrimination between KIR2DL1 subtypes and KIR2DS1 identifies hierarchies in NK repertoire, education, and tolerance. Front Immunol. 2019;10:734-50. 